\title{
EDUKASI MASYARAKAT TENTANG PEMANFAATAN APLIKASI KESEHATAN ONLINE MELALUI PARTISIPASI PENGEMBANGAN SISTEM INFORMASI
}

\section{COMMUNITY EDUCATION ON THE UTILIZATION OF ONLINE HEALTH APPLICATIONS THROUGH PARTICIPATION OF INFORMATION SYSTEM DEVELOPMENT}

\author{
${ }^{1 *}$ Sri Kusumadewi, ${ }^{2)}$ Rahadian Kurniawan, ${ }^{3)}$ Erlina Marfianti, ${ }^{4)}$ Achmad Khodzim \\ 1,2,4) Jurusan Informatika, Universitas Islam Indonesia \\ 3) Jurusan Kedokteran, Universitas Islam Indonesia \\ Jl. Kaliurang km 14,5 Yogyakarta \\ Email: \\ ${ }^{1 *}$ sri.kusumadewi@uii.ac.id, ${ }^{2}$ rahadian.kurniawan@uii.ac.id, \\ 3)erlina.marfianti@uii.ac.id, ${ }^{4)} 17523064 @$ uii.ac.id
}

\begin{abstract}
ABSTRAK
Adanya pandemi covid-19 dan banyaknya tools yang mendukung kemudahan dalam membangun aplikasi digital menyebabkan maraknya aplikasi layanan kesehatan digital secara online. Aplikasi sistem informasi monitoring kesehatan merupakan salah satu bagian layanan kesehatan yang sangat penting dan informasinya harus diketahui secara cepat dan tepat agar tindakan preventif dan pengobatan dapat dilakukan sedini mungkin. Kegiatan pengabdian kepada masyarakat yang dilakukan mencoba untuk mengikutsertakan masyarakat (Kader Posyandu, Bidan Desa, Poskesdes dan PJ Lansia) untuk merancang antarmuka (tampilan) Aplikasi Sistem Informasi Monitoring Kesehatan Lansia berbasis Android di Desa Bimo Martani. Tujuan utama dari kegiatan ini adalah mengedukasi masyarakat untuk memanfaatkan aplikasi kesehatan bergerak dengan cara mengajak mereka untuk merancang tampilan yang akan digunakan. Kegiatan dilakukan melalui lima tahapan, yaitu: 1) Melakukan koordinasi dengan pengurus PKK dan Bidan Desa Bimo Martani untuk menggali situasi; 2) Melakukan survei untuk memotret kondisi awal pemakaian aplikasi; 3) Pengembangan prototipe awal; 4) Penjaringan masukan terkait evaluasi antarmuka aplikasi melalui FGD; dan 5) Penyempurnaan aplikasi. Hasil FGD memberikan masukan kepada tim bahwa aplikasi yang dibutuhkan memiliki antarmuka yang sederhana namun mencakup informasi penting tentang lansia, Indeks Massa Tubuh diberikan secara numerik sebagai keluaran dari formula penghitungan IMT, dan pemantauan terhadap kesehatan jiwa yang diukur dengan menggunakan Geriatric Depression Scale ditampilkan lengkah demi langkah. Secara umum $100 \%$ peserta akan menggunakan aplikasi ini dan diharapkan mampu melengkapi sistem yang sudah ada di Puskesmas.
\end{abstract}

Kata kunci: Posyandu; Kader; Partisipasi; Lansia

\begin{abstract}
The covid-19 pandemic and the large number of tools that support the development of digital applications have led to many applications for online digital health services. The application of the health monitoring information system is a very important part of health services and the information must be known quickly and accurately so that preventive action and treatment can be carried out as early as possible. This service activity invites the community (Posyandu Cadres, Village Midwives, Poskesdes and Person in Charge of the Elderly) to design an Android-based Elderly Health Monitoring Information System Application interface in Bimo Martani Village. The main objective of this activity is to educate the public to use mobile health applications by inviting them to design the display they will use. The activity is carried out in five stages, as follows: 1) Coordinating with PKK administrators and Bimo Martani Village Midwives to explore the situation; 2) Conducting a survey to the community to see the initial conditions of using the application; 3) Development of application prototypes; 4) Selection of input related to evaluation of application interface through FGD; and 5) Application improvements. The essence of this activity lies in step 4. The results of the FGD provided input to the team that the required application has a simple interface but includes important information about the elderly, Body Mass Index is given numerically as the output of the BMI calculation formula, and monitoring of mental health is measured using the Geriatric Depression Scale are displayed step by step. In general, 100\% of
\end{abstract}


participar.
the Puskesmas.

Keywords: Posyandu; Cadre; Partisipation; Elderly

Submitted : 18 September 2020 Revision : 27 September 2020 Accepted : 31 Maret 2021

\section{PENDAHULUAN}

Di Indonesia, layanan kesehatan secara online mulai banyak digunakan. Layanan yang paling marak digunakan adalah layanan konsultasi kesehatan (Hadyan, 2019) (JPPN, 2018). Kualitas layanan kesehatan merupakan salah satu faktor penentu peningkatan kualitas kesehatan masyarakat. Layanan kesehatan digital saat ini menjadi kebutuhan yang sangat penting. Kondisi pandemi covid-19 dan banyaknya fasilitas yang mendukung kemudahan membangun aplikasi digital merupakan dua hal yang menyebabkan menjamurnya aplikasi layanan kesehatan digital secara online. Layanan dokter 24 jam secara online semakin marak di era pandemi ini (Hasibuan, 2020).

Walaupun layanan konsultasi kesehatan ini cukup banyak, namun belum semua masyarakat memanfaatkannya secara maksimal, bahkan sebagian masyarakat juga belum mengenal aplikasi ini. Tercatat baru sekitar $10 \%$ penduduk Indonesia yang menggunakan aplikasi ini (Petriella, 2019). Salah satu penyebabnya adalah belum meratanya kualitas jaringan internet di Indonesia. Penyebab lain adalah rasa kurang percaya dan merasa tidak aman terhadap data pribadi dan ketepatan hasil diagnosis.

Selain aplikasi konsultasi kesehatan online, aplikasi monitoring kesehatan juga penting dikembangkan. Hal ini bertujuan agar dokter, paramedis, maupun masyarakat dapat memantau kesehatan diri dan keluarga dengan cepat sehingga langkah-langkah preventif dan pengobatan dapat dilakukan sedini mungkin apabila terjadi kondisi tertentu. Aplikasi Sistem Informasi Posyandu untuk Ibu dan Anak telah dikembangkan dan diujicobakan di Desa Bimo Martani, Ngemplak, Sleman DIY (Kusumadewi, Kurniawan, \& Wahyuningsih, 2019). Desa Bimo Martani terletak di Kecamatan Ngemplak Kabupaten Sleman,
Daerah Istimewa Yogyakarta yang memiliki area seluas 576.466 hektar. Sebagian besar penduduknya memiliki mata pencaharian sebagai petani. Walaupun saat ini aplikasi Sistem Informasi Posyandu tersebut masih terus dalam proses pengembangan, namun Bidan dan Kader Posyandu merasa perlu menggunakan aplikasi ini demi kemudahan pengelolaan data.

Kebutuhan akan penggunaan aplikasi kesehatan ini mengharuskan adanya edukasi kepada masyarakat akan pentingnya layanan kesehatan secara cepat berbasis teknologi informasi. Berbagai macam cara dapat dilakukan sebagai upaya edukasi, seperti pelatihan, penyuluhan hingga melibatkan masyarakat secara langsung dalam proses pengembangan aplikasi. Pelibatan masyarakat secara langsung dalam pengembangan aplikasi ini bertujuan agar aplikasi yang dibangun sesuai dengan kebutuhan pengguna, minimal memiliki antarmuka yang menarik dan mudah digunakan.

Pada kegiatan Pengabdian kepada Masyarakat (PkM) ini, tim pelaksana mencoba untuk mengikutsertakan masyarakat di Desa Bimo Martani untuk turut merancang aplikasi berbasis Android untuk Monitoring Kesehatan Lansia melalui kegiatan Posyandu Lansia. Posyandu Lansia diadakan dengan tujuan untuk meningkatkan kesejahteraan lansia, baik fisik maupun psikologis agar mandiri dalam masyarakat (Ramadhan, 2016)

Tujuan utama dari kegiatan ini adalah mengedukasi masyarakat, dalam hal ini Kader Posyandu, untuk menggunakan aplikasi kesehatan online dengan cara mengajak masyarakat untuk merancang aplikasi yang akan digunakan tersebut. Fokus utama aplikasi yang akan dikembangkan adalah sistem informasi monitoring kesehatan lansia melalui Posyandu Lansia. 
METODE

Kegiatan PkM ini dilakukan melalui tahapan sebagai berikut:

1. Melakukan koordinasi dengan pengurus PKK dan Bidan Desa Bimo Martani untuk menggali situasi yang ada di desa tersebut dan kebutuhan aplikasi kesehatan berbasis teknologi informasi di desa tersebut. Secara formal kegiatan ini dilakukan sebanyak dua kali, yaitu pada tanggal 13 Februari 2020 dan tanggal 11 Maret 2020. Pada koordinasi kedua dilibatkan beberapa mahasiswa yang akan membantu membangun aplikasi. Pada tahap pertama ini diperoleh informasi terkait kebutuhan aplikasi kesehatan online dan fitur-fitur dasar yang dibutuhkan untuk aplikasi sistem informasi monitoring kesehatan lansia di Desa Bimo Martani.

2. Melakukan survei ke masyarakat untuk memotret kondisi awal pemakaian aplikasi berbasis teknologi informasi di Desa Bimo Martani. Survei dilakukan kepada ibu-ibu PKK di desa tersebut. Instrumen yang digunakan adalah kuisioner yang disebar secara online melalui Google Form.

3. Pengembangan prototipe awal aplikasi sistem informasi berbasis Android untuk monitoring kesehatan lansia. Prototipe yang dibangun pada tahap ini masih belum sempurna. Desain prototipe sebatas pada pengetahuan pengembang dengan masukan yang diperoleh dari Bidan Desa melalui tahap-1 dan informasi tambahan dari kajian literatur. Sumber data dan proses bisnis diperoleh melalui buku Pedoman Pelaksanaan Kegiatan Posyandu Lanjut Usia (Komnas, 2010)

4. Penjaringan masukan terkait evaluasi antarmuka (tampilan) aplikasi dari Kader Posyandu (sebanyak 12 Kader), Bidan Desa, Poskesdes, dan Penanggung Jawab (PJ) Lansia Puskesmas Ngemplak I Sleman terhadap prototipe yang telah dirancang pada tahap-3. Aktivitas ini dilakukan dengan cara Focus Group Discussion (FGD) secara online melalui aplikasi Zoom. Proses FGD didukung sepenuhnya oleh Puskesmas Ngemplak I yang telah menyediakan fasilitas untuk koneksi Internet. Hasil yang diperoleh pada tahap ini adalah masukan-masukan terkait aplikasi diantaranya meliputi: kesesuaian kebutuhan informasi, ragam dialog, dan hak akses.

5. Penyempurnaan aplikasi yang dilakukan oleh pengembang dengan terus melakukan komunikasi dengan pengguna untuk menjamin bahwa aplikasi yang dibangun sudah sesuai dengan kebutuhan pengguna dan mencakup informasi penting yang dibutuhkan oleh Puskesmas.

\section{HASIL DAN PEMBAHASAN}

\section{Hasil Survei Pendahuluan}

Survei pendahuluan ditujukan kepada ibuibu PKK desa Bimo Martani. Sebanyak 19 anggota PKK aktif memberikan respon terhadap kuesioner yang dibagikan. Sebagian besar responden berusia $35-45$ tahun sebanyak 53\% (Gambar 1a) dengan jenjang pendidikan terbanyak adalah SMA/sederajat sebanyak 63\% (Gambar 1b)

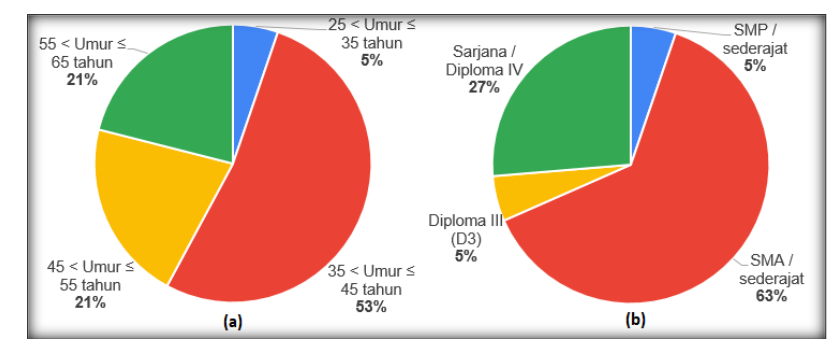

Gambar 1. (a) Umur; (b) Jenjang Pendidikan.

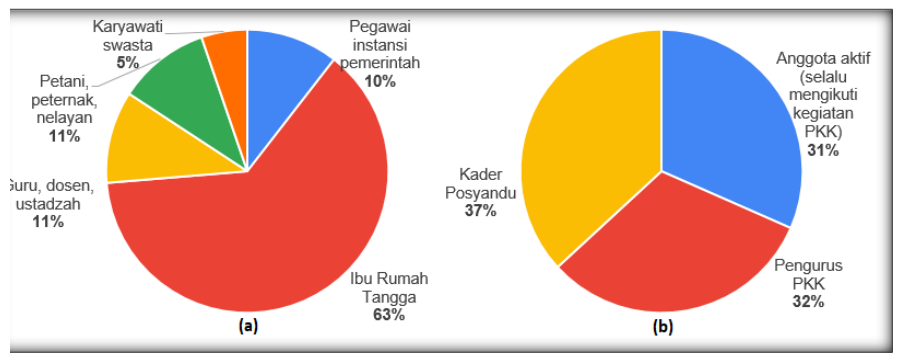

Gambar 2. (a) Pekerjaan; (b) Kedudukan PKK.

Sebagian besar responden adalah ibu rumah tangga sebesar 63\% (Gambar 2a). Aktivitas mereka di Posyandu adalah peserta aktif dengan 37\% adalah Kader Posyandu, 32\% Pengurus PKK, dan 31\% adalah anggota PKK aktif. Karena sebagian besar Kader Posyandu adalah ibu rumah tangga, maka mereka akan 
lebih terampil mengoperasikan smartphone daripada mengoperasikan laptop.

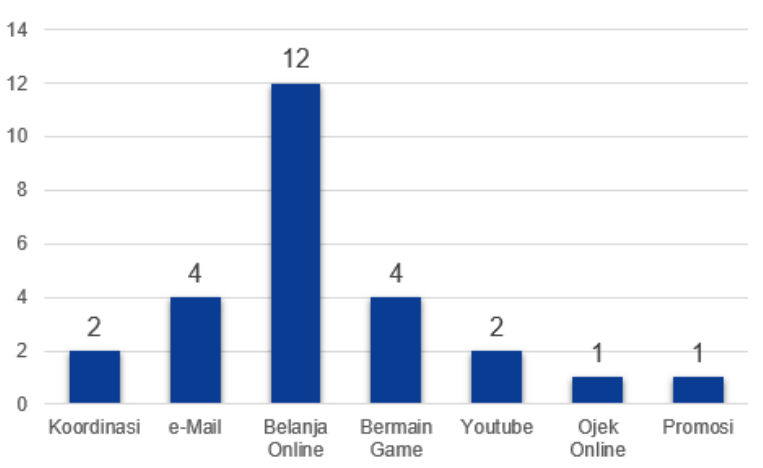

Gambar 3. Penggunaan Smartphone.

Selain untuk menjalankan aplikasi media sosial seperti Whatsapp (WA), Facebook (FB), Instagram, dll, sebagian besar responden menggunakan smartphone untuk keperluan belanja online dan ada juga yang menggunakan smartphone sebagai media promosi produk seperti kuliner (Gambar 3).

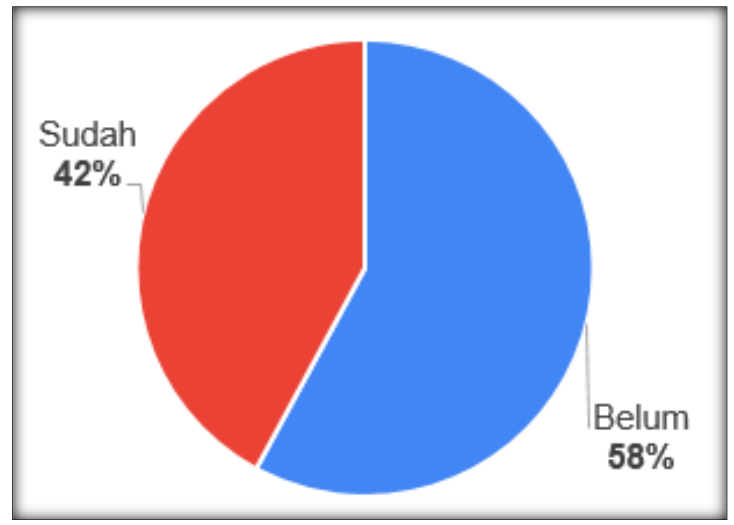

Gambar 4. Pengetahuan tentang Aplikasi Kesehatan Online.

Penggunaan smartphone untuk mengakses aplikasi kesehatan secara online masih belum banyak, bahkan baru $42 \%$ responden yang mengetahui adanya aplikasi ini (Gambar 4). Aplikasi yang digunakan bagi yang sudah pernah menggunakan aplikasi adalah Alodokter dan HaloDoc. Selanjutnya diberikan pemahaman atas aplikasi online ini. Setelah mereka diberikan pemahaman sekilas tentang aplikasi kesehatan online, sebanyak 79\% responden mengatakan tertarik (Gambar 5) untuk menggunakan dan sisanya merasa belum atau tidak tertarik. Beberapa alasan yang menyebabkan mereka belum atau tidak tertarik adalah aplikasi dianggap sulit, masih belum tahu manfaatnya, belum membutuhkan (merasa tidak perlu), dan tidak ingin memanfaatkan kuota data internetnya pada aplikasi yang jarang digunakan.

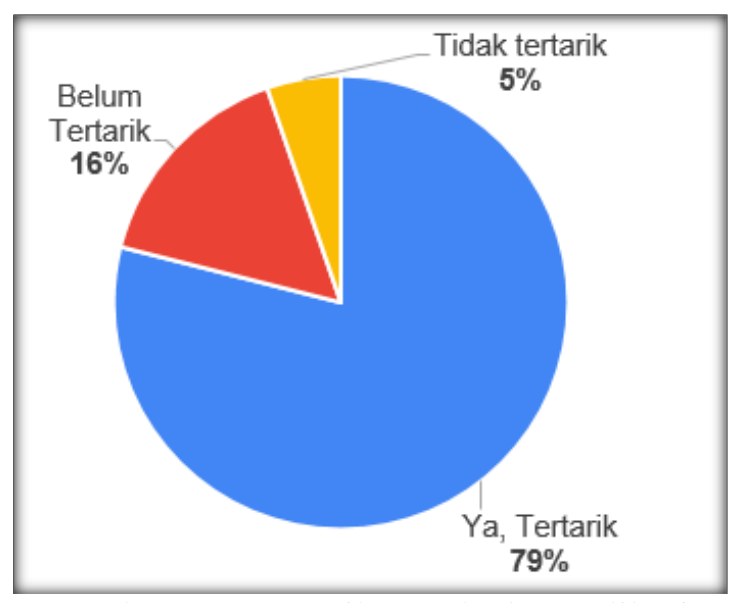

Gambar 5. Ketertarikan terhadap Aplikasi Kesehatan Online.

Namun demikian dari hasil survei tersebut diperlihatkan juga bahwa 100\% responden merasa perlu adanya aplikasi yang dapat merekam data kesehatan keluarga, ibu \& anak, dan kesehatan lansia secara online yang difasilitasi oleh Posyandu.

\section{Prototipe Aplikasi Sistem Informasi Posyandu Lansia}

Aplikasi Sistem Informasi Posyandu Lansia atau Aplikasi Sistem Informasi Monitoring Kesehatan Lansia dibangun berbasis Android. Prototipe awal yang dikembangkan memuat tiga fitur utama yaitu: Identitas Lansia (Gambar 6b), Pemantauan Kesehatan Lansia (Gambar 6c), dan Kartu Menuju Sehat (KMS) Lansia (Gambar 6a).

Sistem ini didukung oleh sistem berbasis web untuk keperluan pemasukan data master. Partisipasi Kader Posyandu dalam merancang tampilan sistem hanya dibatasi untuk sistem yang berbasis Android. Spesifikasi perangkat Smartphoe agar sistem dapat berjalan baik adalah:

a. Sistem Operasi : Android 9.0 (Pie) Ke atas

b. RAM : setidaknya memiliki ram $1 \mathrm{~GB}$

c. Processor : disarankan 1.2 Ghz ke atas 
d. Memiliki Koneksi Internet

e. Memiliki setidaknya kapasitas $50 \mathrm{Mb}$ dipenyimpanan

f. Memiliki Ukuran Layar Minimal 5.5 Inch

Bagi Kader di Desa Bimo Martani, perangkat dengan spesifikasi ini telah difasilitasi pada Program Kemitraan Masyarakat Dikti tahun 2019.

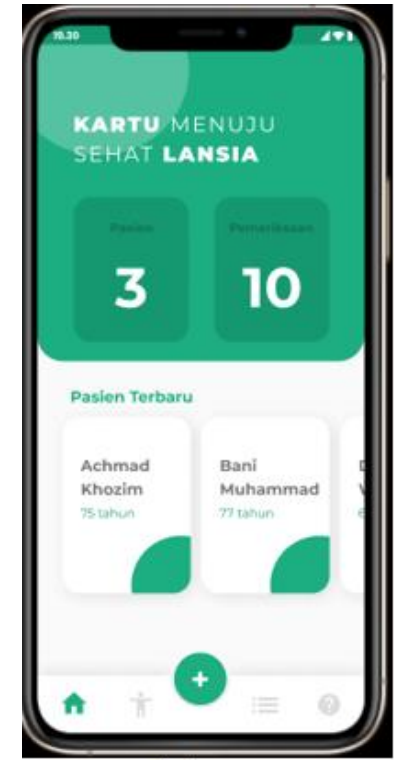

(a)

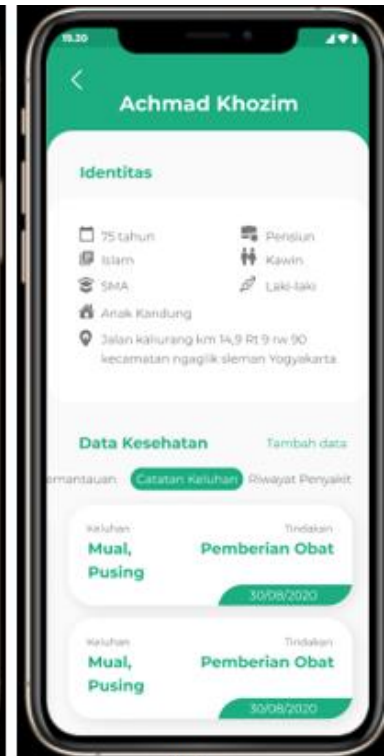

(b)
Gambar 6. Prototipe: (a) KMS Lansia; (b) Identitas.

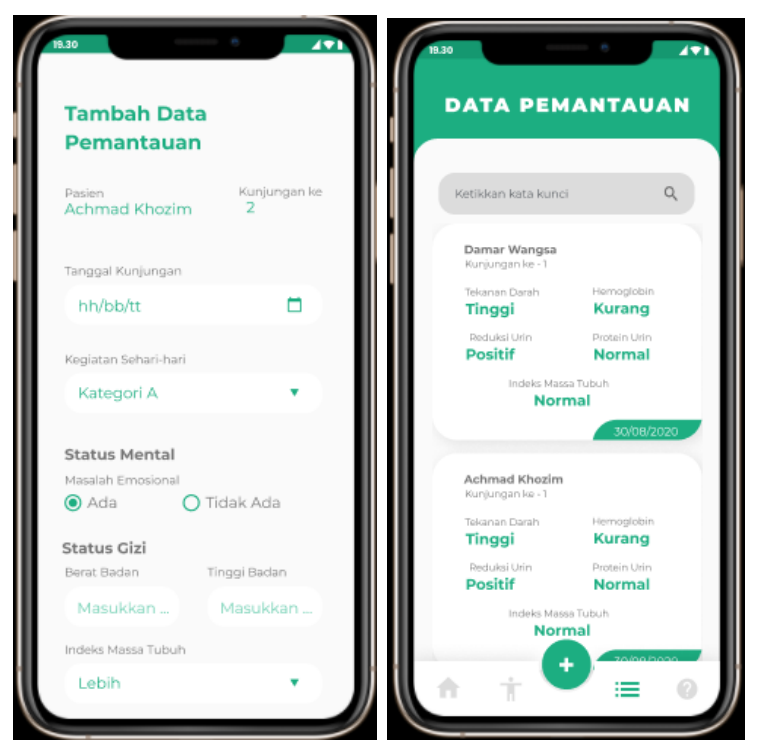

Gambar 7. Pemantauan Kesehatan Lansia.

Sesuai dengan masukan yang diberikan oleh Kader Posyandu, Bidan, PJ Lansia dan Poskesdes, aplikasi ini dapat diakses oleh
Kader Posyandu, Bidan Desa, Dokter Puskesmas, Pendamping Lansia, Kader Poskesdes, Psikolog, dan PJ Lansia sebagai pemegang hak akses utama. Tidak menutup kemungkinan Lansia juga memiliki hak akses. Walaupun tidak sebanyak usia produktif, menurut data dari BPS sebanyak 41,81\% lansia mengunakan HP dan 5,73\% mengunakan Internet (BPS, 2018). Tambahan hak akses dapat diberikan untuk akses website kepada Promkes, Perawat, Petugas Entry Data di Puskesmas, dan Bagian Gizi.

\section{Hasil FGD Evaluasi Antarmuka Aplikasi}

Antarmuka pengguna (user interface) adalah salah satu komponen sistem berbasis komputer yang memfasilitasi interaksi antara pengguna dengan komputer. Antarmuka yang baik akan memudahkan komunikasi antara pengguna dengan komputer sehingga tujuan dikembangkannya sistem akan tercapai.

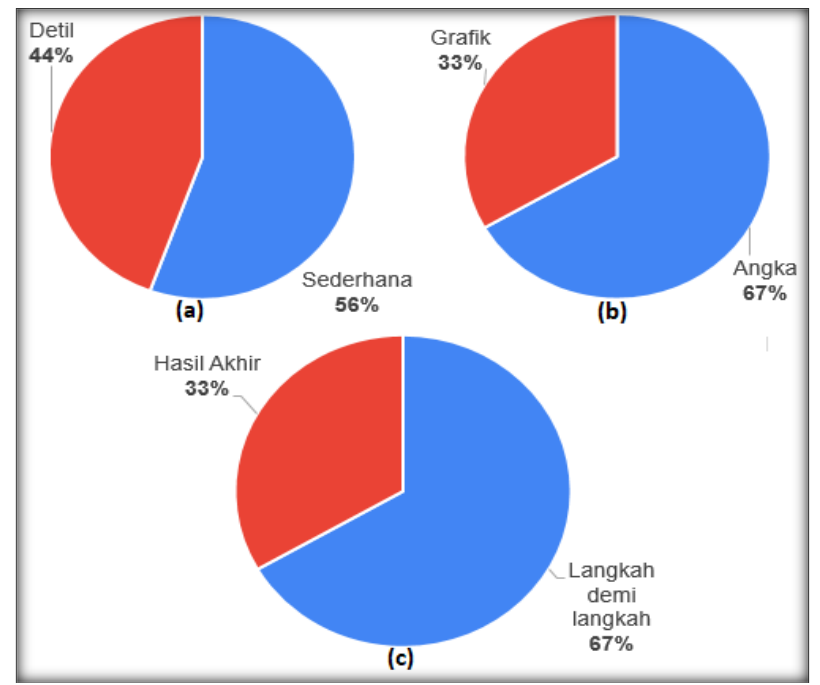

Gambar 8. Kebutuhan Fitur Aplikasi Monitoring Kesehatan Lansia: (a) Penyajian Informasi; (b) Tampilan Hasil KMS Lansia;

(c) Tampilan Hasil GDS.

Salah satu kelemahan yang sering dijumpai pada aplikasi sistem informasi di pedesaan adalah antarmuka (tampilan) dan kontrol sistem komputer tidak dapat disesuaikan untuk memenuhi harapan pengguna (Yuan-Han Huang, 2016) sehingga pada akhirnya sistem tidak dapat digunakan secara maksimal. 
Berdasarkan tipe pengguna, aplikasi ini akan digunakan oleh naive user, yaitu pengguna yang hanya mengetahui sebagian kecil dari sistem (Saha, Mandal, \& Pal, 2015). Oleh karena itu aplikasi harus dibuat sesederhana mungkin namun tetap berisi informasi yang lengkap dan mengikuti aliran kerja dari kegiatan Posyandu Lansia. Sebanyak $56 \%$ responden menghendaki aplikasi dibuat sesederhana mungkin dan $44 \%$ menginginkan detil (Gambar 8a).

Untuk fitur informasi KMS Lansia, 67\% memilih berbentuk angka berupa hasil Indeks Massa Tubuh (IMT) dan 33\% memilih berbentuk grafis (Gambar 8b). Berdasarkan rekomendasi dokter spesialis penyakit dalam, tampilan untuk IMT memang lebih baik berupa angka yang diperoleh langsung dari formula pengukuran IMT. Penggunaan tampilan dalam bentuk angka ini juga memudahkan untuk mengetahui informasi kesehatan lansia. Faktor mudah dipelajari, mudah menjadi terampil, dan mudah digunakan merupakan tiga hal yang wajib dipenuhi agar sistem yang dibangun dapat digunakan dengan baik oleh pengguna (Nurlifa, Kusumadewi, \& Kariyam, 2014).

Salah satu fitur yang harus ada pada Sistem Informasi Monitoring Lansia adalah pemantuan kondisi kejiwaan lansia yang diukur dengan menggunakan alat ukur Geriatric Depression Scale (GDS). GDS digunakan sebagai penyaring dan deteksi dini dari adanya gangguan pada status mental dan kognitif lansia (Kemenkes, JUKNIS INSTRUMEN Pengkajian Paripurna Pasien Geriatri (P3G), 2017). Untuk fitur informasi hasil GDS, sebanyak $67 \%$ responden memilih ditampilkan langkah demi langkah dan sebanyak 33\% responden memilih langsung diberikan hasil akhir (Gambar 8c). Informasi yang disajikan langkah demi langkah akan memberikan informasi lebih kepada Kader atau Bidan tentang kondisi setiap item penilaian sehingga kondisi kejiwaan lansia dapat dilihat secara detil sesuai dengan item pertanyaan yang diberikan. Hal ini sejalan dengan harapan Pemerintah bahwa pemeliharaan kesehatan pada lansia seyogyanya lebih mengutamakan promotif dan preventif (Kemenkes, Peraturan Menteri
Kesehatan Republik Indonesia no 25 Tahun 2016, 2016)

Secara umum semua Kader Posyandu, Bidan, PJ Lansia dan Poskesdes mendukung adanya Sistem Informasi Monitoring Kesehatan Lansia berbasis Android. Partisipasi pengguna dalam proses pengembangan sistem ini akan mempengaruhi tingkat keberhasilan pengembangan sistem tersebut, meningkatkan tingkat kepuasan pengguna, meningkatkan kualitas sistem, dan pada akhirnya dapat menyebabkan keberhasilan implementasi sistem (Adi, 2006).

Adanya sarana yang memadai serta dukungan dari aparat desa dan Puskesmas setempat merupakan hal penting yang memotivasi Kader Posyandu untuk menggunakan aplikasi teknologi informasi dan selalu ingin memutakhirkan wawasan terhadap teknologi baru. Hal ini sejalan dengan penelitian yang telah dilakukan oleh (Tristanti \& Khoirunnisa, 2018). Semua ini dilakukan demi peningkatan kualitas layanan Kader terhadap kesehatan masyarakat.

\section{SIMPULAN}

Kesimpulan yang dapat diambil dari kegiatan pengabdian kepada masyarakat ini adalah bahwa sebanyak $79 \%$ responden anggota PKK aktif Desa Bimo Martani tertarik untuk menggunakan aplikasi kesehatan online. Berdasarkan hasil FGD dengan Bidan Desa, Kader Posyandu, dan Poskesdes diperoleh hasil bahwa aplikasi yang dibutuhkan memiliki antarmuka yang sederhana namun mencakup informasi penting tentang lansia; Indeks Massa Tubuh (IMT) diberikan secara numerik sebagai keluaran dari formula penghitungan IMT; dan pemantauan terhadap kesehatan jiwa yang diukur dengan menggunakan GDS ditampilkan lengkah demi langkah. Selain itu, Bidan Desa, Kader Posyandu, dan Poskesdes berkeinginan/ menerima aplikasi ini.

\section{UCAPAN TERIMA KASIH}

Dengan terselenggaranya kegiatan ini, tim menyampaikan ucapan terimakasih yang sebesar-besarnya kepada Direktorat Penelitian dan Pengabdian Masyarakat (DPPM) UII atas 
dukungan hibah pengabdian kepada masyarakat dengan skim Unggulan tahun anggaran 2020; Kepala Desa Bimomartani atas dukungan dan motivasinya kepada para Kader Posyandu; dan Kepala Puskesmas Ngemplak I Sleman atas fasilitas dan kemudahan penyampaian informasi ke Kader Posyandu Desa Bimo Martani.

\section{DAFTAR PUSTAKA}

Adi, P. H. (2006). Partisipasi Pengguna dalam Pengembangan Sistem Informasi (Telaah Literatur) . Jurnal Akuntansi dan Keuangan, 8(1), 52-61.

BPS. (2018). Statistik Penduduk LAnjut Usia. Jakarta: Badan Pusan Statistik.

Hadyan, R. (2019, 12 10). Layanan Kesehatan Online Makin Marak, Regulasi Belum Memadai. Retrieved from Bisnis.com: https://lifestyle.bisnis.com/read/201912 10/106/1179891/layanan-kesehatanonline-makin-marak-regulasi-belummemadai

Hasibuan, L. (2020, 03 31). Imbas Corona, Layanan Dokter Online 24 Jam Makin Ramai di RI. Retrieved from CNBC Indonesia:

https://www.cnbcindonesia.com/lifestyl e/20200331105255-33-148687/imbascorona-layanan-dokter-online-24-jammakin-ramai-di-ri

JPPN. (2018, 11 21). Pengobatan Jarak Jauh Makin Diminati Masyarakat. Retrieved from JPPN.com: https://www.jpnn.com/news/pengobatan -jarak-jauh-makin-diminati-masyarakat

Kemenkes. (2016, 4 1). Peraturan Menteri Kesehatan Republik Indonesia no 25 Tahun 2016. Retrieved from Kemenkes: https://extranet.who.int/countryplanning cycles/sites/default/files/planning_cycle _repository/indonesia/indonesia_nationa 1_action_plan_for_elderly_2016-19.pdf

Kemenkes. (2017, - -). JUKNIS INSTRUMEN Pengkajian Paripurna Pasien Geriatri (P3G). Retrieved from Kementrian Kesehatan Republik Indonesia: http://kesga.kemkes.go.id/images/pedo man/Juknis\%20P3G.pdf

Komnas, L. U. (2010). Pedoman Pelaksanaan Posyandu Lanjut Usia. Jakarta: -.

Kusumadewi, S., Kurniawan, R., \& Wahyuningsih, H. (2019). IImplementasi Sistem Informasi Posyandi berbasis web dan Android di Desa Bimo Martani. Jurnal Pengabdian \& Pemberdayaan Masyarakat (JPPM), 3(2), 351-359.

Nurlifa, A., Kusumadewi, S., \& Kariyam. (2014). Analisis Pengaruh User Interface Terhadap Kemudahan Penggunaan Sistem Pendukung Keputusan Seorang Dokte. Prosiding SNATIF (pp. 333-340). Kudus: UMK Kudus.

Petriella, Y. (2019, 08 19). Penggunaan Aplikasi Kesehatan di Indonesia Baru 10\% dari Total Penduduk. Retrieved from Bisnis.com: https://ekonomi.bisnis.com/read/201908 19/12/1138279/penggunaan-aplikasikesehatan-di-indonesia-baru-10-daritotal-penduduk

Ramadhan, K. (2016, 5 23). Mengapa Posyandu Juga Penting bagi Lansia? Retrieved from Klik Dokter: https://www.klikdokter.com/infosehat/read/2697604/mengapa-posyandujuga-penting-bagi-lansia

Saha, D., Mandal, A., \& Pal, S. (2015). User Interface Design Issues for Easy and Efficient Human Computer Interaction: An Explanatory Approach. International Journal of Computer Sciences and Engineering; 3(1), 127135.

Tristanti, I., \& Khoirunnisa, F. N. (2018). Kinerja Kader Kesehatan dalam Pelaksanaan Posyandu di Kabupaten Kudus. Jurnal Ilmu Keperawatan dan Kebidanan; 9(2), 192-199.

Yuan-Han Huang, A. K. (2016). Recommendations for Health Information Technology 
Sri Kusumadewi, Rahadian Kurniawan, Erlina Marfianti, Achmad Khodzim

Edukasi Masyarakat Tentang Pemanfaatan Aplikasi Kesehatan Online Melalui Partisipasi Pengembangan Sistem Informasi

Implementation in Rural Hospitals.

International Journal of Health Care

Quality Assurance; 29(4),

https://www.emerald.com/insight/conte

nt/doi/10.1108/IJHCQA-09-2015-

0115/full/html. 